\title{
Special issue dedicated to Anna Brainina
}

\author{
Daniel Mandler
}

Published online: 28 May 2013

(C) Springer-Verlag Berlin Heidelberg 2013

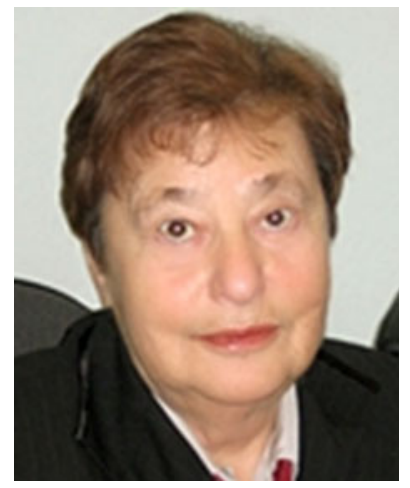

This special issue is dedicated with very warm wishes to Professor Khiena Zalmanovna Brainina, or the way everybody calls her Anna, who is one of the pillars in electroanalytical chemistry for more than half a century. She is undoubtedly the pioneer in the USSR as well as internationally using stripping voltammetry with solid electrodes. Her work is characterized by very deep understanding of electrochemical fundamentals. She is not an analytical chemist who is only interested in the analytical performance of the methods she has developed but in the very basics of the methods.

Anna published more than 150 papers starting in 1965 when she applied polarography on graphite electrodes for the determination of primarily metals. At that time, she started working at the Department of Physical and Analytical Chemistry in Sverdlovsk (now Ekaterinburg) Institute of National Economy. In 1969, she published her first review in Talanta "Film Stripping Voltammetry" where she described a new electrochemical method that enabled

\section{Mandler $(\square)$}

Institute of Chemistry, The Hebrew University of Jerusalem,

Edmond J. Safra Campus,

Jerusalem 91904, Israel

e-mail: daniel.mandler@mail.huji.ac.il detection of nanomolar concentration of metallic species. Anna was among the few Russian electrochemists who successfully published scientific papers in Western journals long before the Cold War ended. Professor Brainina published numerous papers in stripping (inverse) voltammetry. She has improved dramatically the sensitivity and as a result applied her methods to the analysis of natural waters. Anna suggested using the term inverse voltammetry. She wrote "when applied to the investigation of organic compounds, is evidently preferable to stripping analysis, as during the measurement process the substance is not always removed from the electrode surface." And indeed she applied inverse voltammetry to determine a wide range of organic species such as nucleic acids. Professor Brainina has always been very practical. She did not limit herself to academic investigations but made all the way to the commercial product. In the 1980s, she automated her methods and applied them for monitoring the levels of heavy metals in natural waters and other environments. Most of this research was published initially in the Russian journal Industrial Laboratory. Over the years, she published many reviews dealing with voltammetry, in situ modified electrodes in stripping voltammetry, and many more. In 1994, she published her first paper on adsorptive stripping voltammetry using disposable electrodes. Anna showed that thin mercury films could be electrochemically deposited on graphite and applied for voltammetry. She has made tremendous contribution to the electrochemical determination of heavy metals by voltammetry being among the pioneers in Russia to focus in environmental electrochemistry and also addressed food analysis. Since 2006, Brainina found interest in studying antioxidant compounds and the determination of the total antioxidant activity. Recently and while approaching her $80 \mathrm{~s}$, she demonstrated that potentiometry could be used as a method for antioxidant activity. Moreover, she discovered another interesting activity comparing the electrooxidation of metallic nanoparticles with bulk material. 
I had the privilege of meeting Anna a few times and working for a long time with one of her coworkers Dr. Iva Turyan. Anna never seemed to take a break but instead jumped from one meeting to the other as a drop of mercury while keeps being updated and interested in new ideas, products, and basic research. Professor Brainina is still very active and continues to enter new fields of research. We and the entire electrochemistry community wish Anna many more years of fruitful activity!

Brief biography:

Khiena Zalmanovna Brainina was born in Volgograd, Russia, May 26, 1930

1953: Graduation from Ural State University (Sverdlovsk (now Ekaterinburg), Russia): Master of Science in Physical Chemistry

1954-1957: PhD Studies in Physical Chemistry: Ural State University, Sverdlovsk (under supervision of Prof. A. G. Stromberg)
1959-1968: Chief of the analytical laboratory in the Research Institute of Chemistry, Donetsk, Ukraine

1967: Doctor in Science, Moscow State University (Prof. A.N. Frumkin)

1969: Professor of Chemistry at Ural State Economic University, Sverdlovsk, Russia

Professor Brainina is an author of a few hundred of scientific publications, ten patents, five monographs on stripping voltammetry, published in Russian by "Chimia" $(1972,1982$, and 1988) and in the USA by "Willey \& Sons" (1974 and 1993).

Professor Brainina was the recipient of Honored Scientist of Russia award in 1995 and she is a member of the Russian Academy of Engineering Science.

She is the daughter of Zalman Solomonovich Brainin and Mariya Zinov'evna Gladnikova, married to Boris Abramovich Vidrevich in 1954, and has one daughter Marina Vidrevich. 